perception to $20 / 70$. A case of toxic amblyopia from inhalation of the fumes of wood alcohol was restored to almost normal vision and fields after a year's careful treatment. In glaucoma the negative pole will relieve pain and reduce the tension, while the positive will increase both. Dr. Ziegler was able thus to relieve a patient suffering from an attack of acute glaucoma and to prepare her for operation in about ten days. Galvanization of the cervical sympathetic has also proved euccessful in this disease.

$\mathrm{He}$ has tried the sinusoidal current in retinitis pigmentosa and in optic atrophy, but is not overenthusiastic as to the results obtained. $\mathrm{He}$ is sure, however, that it has a future, which only needs to be developed.

Electrolysis is, of course, a most valuable therapeutic measure. In trichiasis it is the only successful epilating agent. The needle is placed at the negative pole and the neck pad is made the positive. It is valuable to shrink up small tumors. In trachoma the bipolar needles will give the best results. In ectropion and angiomata Dr. Ziegler prefers galvano-caustic puncture. He has used corneal electrolysis for leucumata, for powder marks and for corneal ulcers with considerable success. He has modified Alleman's electrode by making the tip convex instead of concave and applying it directly to the sur. face without the intervention of a drop of mercury. Cataphoresis, or the driving of -medicamenus into the ocular tissues by the positive current, should prove to be a valuable measure. In a patient where a heart lesion contraindicated etherization Dr. Ziegler enucleated an eyeball under a cataphorie applica. tion of 20 per cent. cocain for twenty minutes without the patient suffering much discomfort.

Dr. Ziegler concluded by saring that the evidence shoul? convince every careful and unbiased observer that electricity deserves a most honored position in ocular therapeutics.

Dr. George F. Keiper, Lafayette, Ind., stated that he has tried all kinds of eye electrodes and has found that the best electrode is the human finger. By passing the current through his own body and out through the finger to the patient's eye, the physician will not hurt himself or the patient and will avoid any prejudice the patient may have against the use of electricity.

Dr. W. F. Coleman, Chicago, said that his cases were chronic ones and he wished to get electrolysis, which is not in proportion to the voltagn, but to the milliamperage. In opacities in the vitrons, for example, he uses all the milliamperage the patient will stand, usially ten. Dr. Coleman uses the negative pole in hemorrhage while Dr. Zeigler uses the positive, but stated that resuits may be oltained with either pole because the current is low so that it makes little difference. In principle, however. the negative pole is used to dissolve tissue and exudates. In optic atrophy stimulation is desired and the negative pole is used. Dr. Coleman agreed with Dr. Connor that the time required is a disadvantage and that it is often difficult to get patients to continue the treatment sufficiently long. He said that it is impossible to give a prognosis of recovery, but that this applies to other methods of treatment as well, though the day may come when we can. Dr. Coleman said that the most favorable eases of atrophy are traumatic, which have not such a serious basis pathologically as tabes, for instance. He said that he considers Dr. Keiper's suggestion as to the use of the finger a good one in many respects, but confessed that he does not wish to spend the time. He might have patients on three different eurrents at the same time and would not have fingers enough to go round. In regard to regulating the current, he said that the graphite rheostat is unreliable; one may turn on 5 milliamperes and return to the patient in 2 minutes and find that there are 10 . He advised getting a metallic rheostat, not made of German wire, but of a combination metal which is much better. A correct meter is also indispensable.

Naming of Carbon Compounds.-Nitro is a prefix indicating the group-NO. derived from nitric acid by abstracting $\mathrm{OH}$, thus nitroethane, $\mathrm{C}_{2} \mathrm{H}_{5} \mathrm{NO}_{2}$; nitrobenzene, $\mathrm{C}_{6} \mathrm{H}_{5} \mathrm{NO}_{2}$ Glycerin trinitrate, $\left(\mathrm{C}_{3} \mathrm{H}_{5}\left(\mathrm{NO}_{3}\right)_{3}\right.$, is often wrongly called nitroglycerin.-Pharm. Rev., August, 1906.

\section{TOXEMIA OF PREGNANCY.*}

\author{
W. M. JORDAN, M.D. \\ Gynecologist to IIIliman Hospital. \\ BIRMINGHAM, ALA.
}

The pernicious vomiting of pregnancy, acute yellow atrophy of the liver, and eclampsia, are generally grouped together as manifestations of the toxemia of pregnancy. While eclampsia is admittedly a toxemia, it seems unwise to class it with the other two conditions, from which it differs widely in symptoms, pathology, and prognosis, if not in other respects. For this reason it seems to me that eclampsia should be studied entirely apart from the other two types. I wish it to be understood, therefore, that wherever the term toxemia is used in the present article it refers only to the toxemia responsible for pernicious vomiting and acute yellow atrophy and not to eclampsia unless so stated.

The most pronounced lesion to be found postmortem in a case of toxemia of pregnancy is a degeneration and necrosis of the parenchyma of the liver. While this lesion is characteristic of the toxemia of pregnancy, it is not peculiar to it, since practically the same changes may occur in toxemias from other causes, the difference being in degree rather than in kind. For instance, an extreme degree of hepatic necrosis is brought about by phosphorus poisoning. Similar, though less pronounced changes may occur after chloroform anesthesia, as pointed out by Bevan and Favill ${ }^{1}$ and demonstrated experimentally by Offergeld. ${ }^{2}$ Müller's ${ }^{2}$ experiments go to prove that similar effects may follow the administration of ether and other inhalation anesthetics, though the tendency is much less marked than with chloroform. Acute alcohol poisoning has been known to produce fatal necrosis of the liver, as noted by Quincke. ${ }^{3}$ These are examples of hepatic necrosis caused by chemical substances. As an instance of a similar process due to a vegetable poison, Quincke mentions the occasional occurrence of liver necrosis as a result of mushroom poisoning. The liver changes in yellow fever consist of a degeneration and necrosis, not essentially different from that caused by the poisons mentioned above.

The experiments of Traube, quoted by Lusk, ${ }^{4}$ would appear to prove that necrosis of the parenchyma of the liver may be brought about by an excess of bile acids in the blood. This information must be accepted second-hand, if at all, since the reference to Traube's article is not giren by Lusk. Traube's experimen!s might well be repeated with a view to confirming his results. If his observation is correct it throws light on some of the obscure deaths in coma following operations for common duct obstruction. It would also appear to offer a possible explanation of the pathogenesis of acute yellow atrophy of the liver occurring in males and nonpregnant females. It would be reasonable to suppose, for instance, that ordinary catarrhal jaundice, when occurring in an individual whose liver is excessively intolerant of the presence of bile acids in the blood, may induce necrosis of stich a liver in the same way as the various poisons already mentioned. This wonld be an cxample of hepatic necrosis due to the absorption and subsequent poisonous effect of a physiologic secretion. It will thus be seen that necrosis of the liver parenchyma

* Read before the Sonthern Surgical and Gynecological Association, Baltimore, Dec. 11-13, 1906.

1. Acid Intoxication and Late Poisonous Effects of Anesthetics, The Jovrval A. M. A.. Sept. 2-9, 1905.

2. Archiv 1. klin. (hil., 1905, lxxv.

3. Nothnagel's Ency, of Prac. Med.. 1903

4. Science and Art of Midwifery, 1893. 
may be caused by a variety of toxic substances, besides those peculiar to pregnancy.

\section{PATHOGENESIS.}

The source and nature of the toxins which give rise to the fatal liver changes in pregnancy have been the subject of much theorizing, but so far without definite results. The gastrointestinal tract, the liver, the kidney, the ovary, and the ovum, ${ }^{5}$ has each been designated as the source of the toxins, but this entire aspect of the subject is still in so much doubt that it is hardly worth while to go into a discussion of the merits of any particular theory. It is sufficient to say that, whatever its source, it is generally conceded that there is a toxin in the blood which is responsible for the morbid process in the liver.

While little or nothing is known of the source or nature of the toxins which cause the hepatic lesions, something more definite is known of the nature of the lesions themselves. Salkowski's classic experiments on autolysis of the liver were followed by Liefmann's ${ }^{6}$ observation of the similarity of the liver changes in fatal cases of toxemia to those of the autolyzed liver. Furthermore, some of the products arising during the self-digestion of the organ, such as leucin and tyrosin, are also present in the blood and urine in many of the fatal cases of toxemia. There is good reason to believe, therefore, that the liver changes in cases of toxemia are in reality due to a process of self-digestion. It is claimed by Wells $^{7}$ that when the upbuilding function of a living cell is abolished by loss of its nutritive supply or impaired by the action of poisons the last function to be destroved is the property of self-digestion. In Salkowski's experiments anabolism was necessarily abolished owing to the absence of cell nutrition, leaving the catalytic process to go on unhindered. It follows that if the higher vital process of anabolism is impaired or abolished by a poison the cell may attack and destroy itself by autolytic action. The toxins of pregnancy probably induce the liver changes in this way, through the abolition or impairment of the upbuilding function of the liver cells.

Granted that the blood during pregnancy is increasedly toxic, as claimed by Bouchard, ${ }^{8}$ we must then assume an insufficiency of the liver function as an essential factor in the production of the morbid symptoms and lesions of the toxemia of pregnancy. The formula for its production would be insufficient liver and toxemia on the one hand, resulting in failure of the anabolic function and autolysis on the other. The substances in the blood, noxious to the liver cells, would first merely impair the hepatic function, thereby leading to accumulation of the toxins peculiar to pregnancy, as well as those arising from ordinary metabolism, which the liver in its crippled condition is no longer able to neutralize. When the toxemia becomes so severe as to be intolerable, abortion or premature labor is apt to occur through the effort of nature to relieve the condition by removal of the cause, or perhaps as a direct effect of the toxins. This generally occurs before the development of actual necrosis in the liver. The wide-spread destruction of liver cells, as indicated by clinical symptoms, does not ordinarily occur until after the lapse of a period varying from a few hours to a few days after the uteris

5. Edcar. J. Clifton : Clinical Manifestations of the Toxemia of lerenancy, i. Y. Med. Tonr., May 5-12, 1906.

6. Centrally, f. All. Path., xvi, 12.

7. Delayed Chloroform Poisoning and Allied Conditions, Tru Joursal A. M. A., Feb. 3, 1906.

8. Autointorication in Disease, translation by Oliver, 1894. is emptied. In other words, the removal of the primary cause of the toxemia by terminating the pregnancy, appears to have the effect of aggravating the condition, paradoxical as this may seem. This was true in four of my own cases, and is a feature of many of the reported cases of others. This peculiar behavior of toxemia cases is especially noticeable in those which begin as catarrhal jaundice during local epidemics of this disease. These cases do not appear to be at all serious until after delivery, when the symptoms of acute yellow atrophy supervene and lead rapidly to a fatal issue.

This tendency of toxemia cases to become worse after removal of the primary cause is a matter of supreme clinical importance, and it is surprising that it has not attracted more notice from obstetricians. So far as I can learn from the current literature on the subject, there seems to have been no attempt to ascertain its cause or to forestall its effect. Recognition of this peculiarity of these cases forces the conclusion that a new supply of toxins must enter the circulation after the uterus has been emptied. It seems to me that the source of these new toxins is not far to seek. The postpartum uterus loses weight rapidly after being emptied of its contents, the loss during the first week approximating 50 per cent., according to Williams' ${ }^{\prime}$ figures, the freshly delivered uterus weighing about 1,000 grams and only 500 grams one week later. This rapid atrophic process undoubtedly results in large quantities of waste products being thrown into the circulation. The burden of neutralizing these products, which must be toxic inasmuch as they are excrementitious, falls on the liver, which in its crippled condition is unequal to the task. 'The impending necrosis of liver cells then becomes actually established.

Of interest in this connection is the fact that there is reason to believe that the process of involution of the uterus is itself essentially a physiologic autolysis of the organ, rather than a simple atrophy or fatty degeneration, as heretofore taught. This idea is borne out by the occurrence of peptonuria during the puerperium. Levene $^{\mathbf{1 0}}$ refers to it in his article on autolysis, and something like the same idea must have been in the mind of Fischel, ${ }^{11}$ before the advent of the doctrine of autolysis, when he advanced the theory that involution is due to the conversion of the hypertrophied uterine muscle into peptone, and its excretion in the urine. Peptonuria presupposes peptonemia, and, as is well known, peptones and albumoses are toxic when present in the blood. It is not to be inferred, however, that these are the only toxic substances resulting from the retrograde process in the uterus. I presume it will be understood that by the terms peptonuria and peptonemia the presence of albumose in the urine and blood is meant, instead of true peptone, which is never present in either fluid unless artificially introduced.

Granted that the toxins resulting from the retrograde change in the postpartum uterus are apt to be the determining influence in the actual development of an impending necrosis in the liver, the importance of forestalling their effect is obvious. This can only be done by terminating the pregnancy at an earlier date than would otherwise seem necessary. In other words, it is not enough merely to determine whether the liver can withstand the pregnancy toxemia, but allowance must also be made for the additional postpartum dose. An-

9. Obstetries, 1203.

10. Autolysis, Tite Journal A. M. A.. March 17-24, 1906.

11. Ceber puerperale Ieptonurie, Archiv. f. Gyn., 1884, xxiv. 
other element which is no doubt sometimes the determining factor in an unfavorable case is the anesthetic. While this applies especially to chloroform, it must not be forgotten that in order to produce complete anesthesia a toxic dose of an anesthetic is necessary, and, as heretofore stated, all the inhalation anesthetics are to some extent liver poisons.

\section{PATHOLOGY.}

The liver is the principal seat of the pathologic changes induced by the toxemia of pregnancy. The process consists essentially of a degeneration and necrosis of the cells of the liver lobules. Any of the three zones of the lobule described by Virchow may be affected by the necrotic process, but a careful analysis of published reports would indicate that it attacks by preference the central and mid-zonal areas. Schmorli2 believes that necrosis beginning in the peripheral zone is typical of eclampsia, and his views are confirmed by Williams. ${ }^{13}$ Both observers, however, attribute the necrotic process in eclampsia to secondary changes dependent on thrombosis of the vessels in the interlobular spaces. This explanation of the hepatic necrosis in eclampsia serves to support the view advanced by Williams that eclampsia is due to a different kind of toxemia from that giving rise to pernicious vomiting and acute yellow atrophy. According to this explanation the variety of toxemia which gives rise to eclampsia produces thrombosis primarily, the necrotic changes being a secondary effect, while the toxemia which results in pernicious vomiting and acute yellow atrophy is the direct cause of necrosis of the liver cells. Ewing ${ }^{14}$ considers that eclampsia, acute yellow atrophy and pernicious vomiting are simply different manifestations of the same toxemia. While this question remains to be definitely settled, it is my belief that the diversity of the two types of toxemia will ultimately be established. In addition to the well-recognized differences in symptoms and pathology, between acute yellow atrophy and pernicious vomiting on the one hand and eclampsia on the other, there is a striking difference in their behavior after the uterus is emptied. Barring exceptional cases, the tendency of eclampsia is to get better a few hours after delivery, while that of the other variety is unmistakably in the opposite direction. Furthermore, they differ in prognosis, uncomplicated eclampsia being a much less fatal disease than acute yellow atrophy or pernicious vomiting. It is not unlikely that mixed types of toxemia may occur, giving a clinical picture that may be interpreted as eclampsia or acute yellow atrophy, according to the bias of the individual observer. The existence of these mixed types may be the cause of much of the unfortunate confusion in the terminology of this subject.

In addition to the lesions in the liver, degenerative changes are present in the kidneys and heart, and in eclampsia, small thromboses in the brain and lungs.

\section{SYMPTOMS.}

Vomiting is a prominent symptom of toxemia. When occurring in the early months this symptom dominates the picture to such an extent that the condition is classed as a clinical type under the name of pernicious vomiting of pregnancy. This early vomiting is apt to be confused with the benign type due to reflex or neurotic influences,

\footnotetext{
12. Untersuchungen ïher prerneral Eklampsle, Leinzig, 1893.

12. Untersichungen iher puerperal Eklampsie, Leipzig, 1893. 1005.

14. Pathology and Pathogenesis of the Toxemia of Pregnancy, Amer. Jour. Obst., 1005, 1l, 2.
}

but in the later months its significance is not so apt to be overlooked.

Headache is a common symptom, as are also neuralgic pains in other parts of the body. Epigastric pain, probably due to the liver changes, is especially significant. Increased secretion of saliva is an important symptom present in many of the bad cases. It is most noticeable at night during sleep. The patient on waking finds a spot on the pillow, due to the dribbling of saliva from the mouth.

Air hunger, described by Kussmaul ${ }^{15}$ is a fairly constant symptom. It was a prominent feature in three of my four fatal cases and in four out of five cases seen with others.

Extreme mental depression is present in many cases. The patient takes a most gloomy view of her condition and frequently expresses a conviction that she will not recover.

Edema of the extremities or face is frequently noted, although it is by no means a constant feature. Albumin may or may not be present in the urine. Evidences of disturbed metabolism, however, may be rather constantly found.

All these symptoms precede the development of the necrotic process in the liver and are due to the toxemia itself. Those which depend on the destruction of liver cells are coma and stupor, black vomit, bile in the urine, possibly icterus, rapid breathing, convulsions (always in eclampsia, occasionally in acute yellow atrophy), failure of renal function, failure of circulation. Death is the rule after the advent of these grave symptoms, though regeneration of the damaged liver cells and recovery is possible.

\section{DIAGNOSIS.}

Valuable work has been done by Williams, Ewing and others toward establishing laboratory aids to the diagnosis of toxemia of pregnancy. Ewing first called attention to the diagnostic significance of unoxidized proteid derivatives in urine, while Williams was the first to point out the special significance of an increased percentage of ammonia. The normal amount of ammonia in the urine is from 3 to 5 per cent., and Williams considers it a danger signal when the percentage reaches 10 or more. I am in no position to express an opinion as to the practical clinical value of this test, having had no experience with it. There can be no doubt, however, that the test is based on logical grounds. It is well known by physiologists that when in an animal a part of the portal blood is diverted from the liver and carried directly into the general circulation by means of an Eck fistula between the portal vein and vena cava a considerable part of the urea nitrogen appears in the urine as ammonia. ${ }^{18}$ Almost all the urea is represented by ammonia if the liver is entirely shunted out of the circulation by ligature of the hepatic artery and of the portal vein on the liver side of the fistula. In the light of this experimental data it is to be expected that hepatic insufficiency in the human subject would result in a similar disturbance of the ratio between the urea and ammonia output. While there can be no doubt that the presence of an increased percentage of ammonia in the urine is an indication of a dangerous hepatic insufficiency, it is denied by Ewing ${ }^{17}$ that its absence is necessarily of favorable significance. It is to be regretter that the estimation of unoxidized proteid derivatives,

15. Quoted by Bevan and Favill.

16. Schafer, E. A. : Text-book of Physiology, 1898

17. I'ersonal communication, Nov. 19, 1906. 
and especially the ammonia coefficient, is so complex a chemical procedure as to be available only to those who have access to the services of a skilled chemist. The diagnosis must, therefore, continue for the present to rest almost entirely on the clinical symptoms.

\section{TREATMENT.}

Palliative measures, to be effective, must be directed not only against the toxemia but quite as much against the hepatic insufficiency. No method of treatment hitherto employed has appeared to influence favorably the impaired antitoxic function of the liver. Eliminative and dietetic treatment, intended to reduce the toxemia, while sometimes successful, too often merely postpone the crisis, the morbid condition reappearing at a later date in aggravated form. I have seen several cases behave in this way, and many other examples may be found in the literature. In view, therefore, of the impracticability of treating the hepatic insufficiency, and the unreliability of treatment of the toxic condition itself, it seems to me that palliative measures should have no place in the management of a recognized case of toxemia of pregnancy.

Radicalism is, then, the only alternative, and in the interest of the patient it should be resorted to early and without reference to the interest of the fetus. Assuming that the diagnosis is established, the indication to empty the uterus is just as urgent as the indication to operate in a case of recognized ectopic pregnancy before rupture. If the condition arises during the early months the question as to whether to empty the uterus at one sitting or to induce abortion by a slower method must be decided according to the urgency of the case. On account of the possible unfavorable influence of anesthesia, nonoperative induction of abortion should be given preference, other things being equal. This rule should also be followed in the later months for the same reason. A protracted labor should not be permitted, however, as the excessive muscular exertion would add its quota to the toxemia already existing. If the case is very urgent, rapid delivery may be accomplished by means of whatever obstetric operation seems to be best suited to the case. Cesarean section may be performed by either the vaginal or abdominal method, provided that the exigencies of the case appear to call for such an operation. If, however, for any reason it is seen fit to perform the abdominal operation, the question arises as to whether it would not be advisable to remove the uterus at the same time in order to avoid a probable increase in the toxemia as a result of the process of involution.

In any operative procedure on a patient with toxemia inhalation anesthesia should not be employed if it is possible to avoid it, for reasons already stated. Spinal anesthesia, free as it is from the disadvantages of general anesthesia in this condition, is worthy of favorable consideration. In any event, chloroform should never be used in a case of toxemia of pregnancy.

\section{REPORT OF CASES.}

CASE 1.-Mrs. J. P. A., aged 19, primipara, was seen with Dr. Wyatt Heflin.

History.-Pregnancy was uneventful until the beginning of the eighth month, when she contracted what appeared to be an attack of catarrhal jaundice, a disease which was prevalent in the neighborhood at the time. The jaundice continued for two weeks, when labor came on, Jan. 14, 1903, about two weeks before full term. Spontaneous delivery occurred in four hours. The patient's condition was apparently normal except for jaundice, until forty-eight hours after delivery, when she gradually sank into a stupor and died January 17, about seventy-two hours after delivery. A few hours before death she vomited a quantity of coffee-ground material. A specimen of urine obtained just before death contain leucin crystals, and this finding, together with the elinical picture, led to a diagnosis of acute yellow atrophy of the liver. The case was reported as such before the Jefferson County Medical Society, Feb. 9, 1903. Postmortem was not allowed.

CASE 2.-Mrs. A. E. S., primipara.

History.-Pregnancy presented no abnormal feature except edema of extremities and face. The urine was examined repeatedly for albumin and casts, but always with negative results. Labor, about full term, began Sept. 9, 1904. After twenty. four hours' useless labor delivery was accomplished by version. Chloroform anesthesia was used and was somewhat prolonged on account of repairing an extensive perineal laceration. The patient's condition was good until the morning of September 13, sixty hours after delivery, when she was found by the nurse in a partial stupor. This steadily deepened, and jaun. dice appeared a few hours later and rapidly increased. Death occurred September 14, eighty-four hours after delivery. Postmortem was not allowed. Neither leucin nor tyrosin crystals could be found in the urine. A diagnosis of acute yellow atrophy of the liver based upon clinical symptoms alone.

CASE 3.-Mrs. C. H. C., primipara, aged 34.

History.-Nausea and vomiting, with albuminuria, appeared about the end of the third month. The condition improved remarkably on a milk diet and eliminatives. Under this treatment the woman's condition remained apparently normal until the end of the seventh month, when the symptoms re. turned rather suddenly. After a few days of palliative treatment Iabor was induced, and after a tedious labor delivery was accomplished by forceps under chloroform anesthesia. Black vomit appeared while she was still under the anesthetic, and consciousness never fully recovered. Urine was very scanty after delivery, and contained albumin, casts, and bile pigment. Death occurred thirty-six hours after delivery. No postmortem.

CASE 4.-Mrs. I. L. A., second labor.

History of Previous Pregnancy. - She was attended by me in her first labor, May 16, 1901. She had suffered very much from nausea and vomiting during that pregnancy. Delivery was accomplished by forceps. Twenty-four hours after delivery a mild, acute mania developed, which lasted about one week, Convalescence was slow, but finally resulted in complete recovery. She was advised by me not to attempt to go through another pregnancy, but after two years of fairly good health, she again became pregnant in August or September, 1903.

Subsequent Pregnancy.-In this pregnancy she almost lost her life from pernicious vomiting. She steadfastly refused to consent to the induction of abortion until she was in a desperate condition. Abortion was finally induced, however, and she made a slow but satisfactory recovery. She became preg. nant again five months later, and got through the early months very well compared to the previous pregnancies. At the beginning of the sixth month, however, persistent vomiting set in, accompanied by scanty urine and albuminuria. She again refused to consent to having the pregnancy terminated until she began to suffer from "air hunger." She then consented to have labor induced, but her symptoms rapidly grew worse, and she had already sunk into partial coma before the preparations for delivery had been completed. The delivery was accomplished by version, the necessary dilatation of the cervix being obtained by means of the Bossi dilator. The entire proceedings were completed in thirty-five minutes, and without damage to the maternal structures. A very small quantity of chloroform was given, very little being required, owing to the partial stupor. Her pulse was almost imperceptible at the time of operation, and failed to respond to stimulation during and after the delivery. Death occurred four hours after delivery. Postmortem was not allowed.

Case 5.-Mrs. W. G. O., third pregnancy.

History.-The patient suffered from headache, mental depression, edema of face and extremities, insomnia, increasing albuminuria, scanty urine and profuse salivation. No improve- 
ment occurred under palliative treatment. Labor was induced at the seventh month of pregnancy, and a living child was delivered. Recovery was uneventful.

CASE 6.-Mrs. J. D. H., was seen with Dr. R. B. Harkness; third pregnancy.

History.-Eclamptic convulsion had occurred after the first labor. The second pregnancy and labor were uneventful. One convulsion occurred at the fourth month of the third pregnancy. Improvement took place under palliative treatment. The woman had an easy labor at full term. Rapid pulse and labored breathing with partial stupor developed a few hours after labor. The condition was exceedingly grave. Convalescence was slow and complicated by endocarditis and thrombosis of the veins of the left arm.

CASE 7.-Mrs. W. H. T. was seen with Dr. D. F. Talley.

History.-The principal symptoms were "air hunger" and vomiting of coffee-ground material. Pulse was rapid and weak. Premature labor was induced by Dr. Talley and recovery was uneventful.

CASE 8.-Mrs. J. O. T. was seen with Dr. D. F. Talley.

History.-This patient suffered from persistent vomiting of coffee-ground material, which gave the blood reaction with the guaiac test. There were also present mental torpor and profuse salivation. Premature labor was induced by Dr. Talley and recovery was uneventful.

CASE 9.-Mrs. B. was seen with Dr. E. S. Casey.

History.-Spontaneous abortion occurred Sept. 27, 1906, in the third month of pregnancy. The uterus was curetted on account of retained secundines, Oct. 4, 1906, under ether anesthesia. Temperature remained high, and on the day following the curettage, coma and jaundice appeared. The jaundice deepened rapidly, coma became profound and death occurred Oct. 6, 1906, eight days after the abortion. Postmortem was not permitted.

\section{INFLUENCE OF THE MOTHER'S HEALTH IN PREGNANCY ON HER UNBORN CHILD.*}

J. W. BALLANTYNE, M.D., F.R.C.P.E.

President Edinburgh Obstetrical Society: Lecturer on Obstetrics and Gynecology, Surgeons' Ifall and Medical College for Women. EDINBURGH.

There are three epochs of a child's life during which the mother's influence is supreme: The middle period of the three is that of lactation, and it is followed by a time of varying extent, lasting usually till the child goes to school, while it is preceded by an antenatal epoch of at least nine months' duration. It is with the last named of the series only that I am here concerned; but it may make for lucidity if $\mathrm{I}$ indicate briefly the kind of influence which a mother exerts during the other two periods, both of which are distinguished from the third by the fact that they are postnatal. I will call the three epochs in their order: 1, Antenatal; 2, lactational. and, 3 , postlactational.

The postlactational period of influence extends from the time of weaning, which may, perhaps, be stated roughly as occurring at the ninth month of the child's life, to the year when the child goes to school or in some other way passes from under the immediate supervision and control of the mother. During these years, which may be estimated at five or six, the mother's influence over her child is preëminent; it is not, however, exclusive of all others, for the father, or the nurse, or brothers and sisters, may all have a certain degree of control over the health destiny of the young child growing up among them. Nevertheless, the maternal influence far outweighs that of all the rest combined; and it may be stated generally that the mother deter-

* This paper was prepared to be read in the Section on Diseases of Children, at the Fifty-seventh Annual Session held at Boston, June. 1906 mines what shall be the food of her child, what shall be his clothing, what the amount and kind of exercise shall be, what shall be the physical surroundings, and, vastly more subtle, what the moral and religious atmosphere. If she be a wise mother she will endeavor to supply him with food suited to his age and requirements; she will see to it that he is clothed in accordance with the needs of exercise, indoors or outdoors, and with the varying conditions of climate and season; and she will take care that his body hygiene, as well as that of his nursery and playroom, be the best that can be obtained. In all these matters she will ask for, and ought to receive, the best advice from her medical attendant; and, if she employ a trained nurse to look after her child's interests during a part of the day or night, she ought to choose one capable of understanding the reasons for the rules of health in childhood. She will endeavor also to shield her child from epidemic and exanthematous dangers, and from the more persistent and pernicious effects of bad habits acquired in early life. It is no exaggeration to say that, for the proper performance of a mother's functions, as they are mapped out above, a very large part of a mother's time must be set aside. That all women who have borne children are not willing to devote so much time to the business of influencing their offspring's future is a commonplace; but such women can hardly lay claim to the name of mother, for a mother's duties do not cease with the close of the third stage of labor.

In the lactational period, the first nine months of postnatal life, the infant's welfare is even more dependent on the mother's care and interest. Her influence is now more than preëminent; it is practically exclusive. The child is drawing his entire nourishment from the maternal tissues; he is watched over by his mother day and night; nothing, it may be said, can happen to him without her knowledge and consent. Her dietetic errors are reflected in his arrested nutrition; her emotional disturbances and social distractions are transmuted into his digestive disorders, and the direases from which she may suffer may either be passed on to him or in less direct ways, by altering the composition of her milk, may affect the performance of his bodily functions. Should she become pregnant while nursing, both the infant at the breast and the fetus in the uterus will feel the strain that is thus put on her organism. I need not linger over this period of maternal influence, for I think every one admits that the state of an infant is a very fair test of the structural and functional integrity of his nursing mother. Neither, unfortunately, is there any need to inform the medical practitioner that mothers, some of them perhaps from inability, others more likely from disinclination, too often are not found standing in this close relationship to their young infants. There may be dangers to the infant from drawing his supply of milk from her breast, but the dangers are multiplied when he has to depend on the cow or the manufacturer of artificial food, although I freely admit that the cow has often proved a benefactor and that the manufacturer has sometimes shown ability and ingenuity.

THE ANTENATAL PERIOD.

But it is more with the influence of the mother on her child in the antenatal period of his existence that I have to do here. The extent and character of this influence are to a large degree unknown to or unconsidered by many medical men. Too often physicians allow notions of the 